\title{
EFECTO ANTIBACTERIANO IN VITRO DEL CARVACROL (ACEITE DE ORÉGANO) SOBRE CANDIDA ALBICANS
}

\author{
ANTIFUNGAL ACTIVITY IN VITRO CARVACROL \\ (OREGANO OIL) ON CANDIDA ALBICANS
}

\author{
JUAN JESÚS QUINTANILLA BOCÁNGEL
}

Universidad Norbert Wiener

\section{RESUMEN}

El presente trabajo de investigación tuvo como objetivo determinar el efecto antibacteriano in vitro del extracto de aceite de orégano, carvacrol, sobre cepas de Candida albicans. Se preparó el extracto de aceite de orégano, carvacrol, al $0,1 \%$ in vitro, empleando el método de Kirby Bauer (difusión en disco) y la determinación de la concentración mínima inhibitoria (CMI). Para la evaluación, se expuso a Candida albicans a cuatro concentraciones del extracto de aceite de orégano; asimismo, se consideró un grupo control con fluconazol y otro con inóculo microbiano, para luego realizar diez repeticiones en cada caso. Se determinó que existe diferencia estadísticamente significativa entre el efecto antifúngico de las diferentes concentraciones de extracto de aceite de orégano sobre el crecimiento de Candida albicans $(\mathrm{P}<0.05)$ y fue sensible a las cuatro concentraciones al comparar los halos de inhibición según la escala de Durafourd. La CMI para la acción antifúngica fue de $100 \%,(1000 \mathrm{mg} / \mathrm{ml})$. Se concluyó que el carvacrol, como extracto de aceite de orégano, sí tiene efecto inhibitorio in vitro contra Candida albicans.

Palabras clave: carvacrol, Candida albicans, antifúngico.

\section{ABSTRACT}

This research had as objective to determine the antibacterial in vitro effect of the oregano oil extract Carvacrol on Candida albicans. The sample consisted of preparing the extract of oregano oil carvacrol to the $0,1 \%$ in vitro prepared the Kirby Bauer method (disk diffusion) and determination of minimum inhibitory concentration (MIC), therefore, to evaluate the antimicrobial activity of carvacrol was exposed Candida albicans to four concentrations of the extract of oregano oil also there was a control with fluconazole and other microbial inoculum group, and then we did 10 repetitions in each case.

It was determined that there is statistically significant difference between the antifungal effect of different concentrations of extract of oregano oil on the growth of Candida albicans $(\mathrm{P}<0,05)$ and it was sensitive at 4 concentrations of the extract of oregano oil to compare zones of inhibition as measured Durafourd. The MIC for the antifungal activity was $100 \%,(1000 \mathrm{mg} / \mathrm{ml})$. It concluded that the Carvacrol as an extract of oregano oil has Inhibitory effect on Candida albicans.

Key words: Carvacrol, Candida albicans, Anti fungical. 


\section{INTRODUCCIÓN}

Las infecciones producidas por hongos han ido sobresaliendo sobre otras patologías, básicamente por el aumento del número de pacientes con problemas en el sistema inmunológico, pero también debido a las nuevas técnicas de diagnóstico y de tratamiento. Esto crea una mayor población susceptible a contraer este tipo de infecciones oportunistas, en las que el agente patológico más común es la Candida albicans, que puede desencadenar infecciones superficiales, como candidiasis oral y vaginal, y mortales infecciones sistémicas. Las infecciones en mucosas han recibido una especial atención debido al avance de la infección por el virus de la inmunodeficiencia humana $(\mathrm{VIH})^{6,10,12,13}$.

El tratamiento de la candidiasis en mucosas no es complicado en pacientes en los que el sistema inmunológico conserva niveles adecuados y los antifúngicos tópicos resultan eficaces; lo contrario sucede en estados de inmunodepresión, donde existen altas tasas de recurrencias o recidivas de lesiones, que requieren terapia intensiva sistémica y en los que, a pesar de los buenos resultados con antifúngicos azólicos, existen diversas formas clínicas resistentes al tratamiento con ketoconazol, fluconazol e incluso anfotericina $B^{11,12,13}$, todos estos antifúngicos conocidos. Esta fármaco-resistencia, la toxicidad y las interacciones farmacológicas de los antifúngicos comunes fomenta la búsqueda de alternativas terapéuticas en donde los productos naturales, los vegetales entre los más estudiados, son los más indicados para cumplir este objetivo $^{2,4}$.

El carvacrol es un componente de los aceites volátiles de especies de orégano. Los estudios han reportado que es el mayor constituyente natural (70 \%) de los aceites esenciales de plantas aromáticas, cuyas acciones farmacológicas sugieren se deben a sus componentes. Es referido que el carvacrol tiene diferentes actividades biológicas, antimicrobianas, antioxidantes, antimutagénicas, antigenotóxicas, antihepatotóxicas y hepatoprotectoras. Su actividad antimicrobiana ha sido bastante extendida a bacterias patogénicas y algunos hongos, incluyendo aquellos resistentes a drogas y los que constituyen el biofilm dental ${ }^{15,16,17}$.

Por otro lado, la actividad antifúngica del carvacrol no está bien aclarada; se refiere que podría darse por la inhibición de la conversión dimórfica mediante dos mecanismos: El primero, en el sentido de que el carvacrol juega un rol durante la invasión e infección de los tejidos, en la formación del tubo germinal y crecimiento de las hifas. Se ha demostrado que existe una estrecha correlación entre la formación del tubo germinal y el incremento de la adherencia de Candida albicans a las células epiteliales de la mucosa, por lo que se ha sugerido desde entonces que este pudiera ser uno de los mecanismos relacionados con la virulencia por parte de las especies de Candida. El otro mecanismo establece la inhibición de la actividad de la y-glutamil transpeptidasa responsable de la degradación del glutatión, principal regulador no enzimático del equilibrio redox intracelular, durante la elongación de las hifas ${ }^{7,11,12}$.

En el presente trabajo se busca determinar el efecto antibacteriano del aceite de orégano, carvacrol, sobre cepas de Candida albicans.

\section{MATERIALES Y MÉTODOS}

El presente estudio se planteó con un diseño de observación y fue de tipo experi- 
mental, en la que la unidad de análisis la constituyeron los discos de difusión y las placas Petri observadas. Las cepas de Candida albicans ATCC 10231 fueron obtenidas del Laboratorio de Microbiología de la Facultad de Medicina Humana de la Universidad Peruana Cayetano Heredia y sembradas en placas Petri, conteniendo agar Sabouraud y material botánico a diferentes concentraciones del extracto de aceite esencial de orégano, carvacrol, $25 \%$ (250 mg/ml), $50 \%$ (500 mg/ml), $75 \%$ $(750 \mathrm{mg} / \mathrm{ml})$ y $100 \%(1000 \mathrm{mg} / \mathrm{ml})$. Se determinó un tamaño de muestra de 10 observaciones para cada concentración de aceite esencial de orégano, carvacrol, para Candida albicans: 10 repeticiones, colocándose a la concentración de $25 \%$, $50 \%, 75 \%$ y $100 \%$.

Luego de sembrar la cepa de Candida albicans ATCC 10231 en placas Petri, se realizó la prueba de susceptibilidad utilizando el método de Difusión de Discos o método de Kirby-Bauer. Se prepararon discos de papel filtro estériles y se les sumergió dentro de cada una de las concentraciones de extracto de aceite de orégano, carvacrol: $25 \%(250 \mathrm{mg} / \mathrm{ml}), 50 \%$ (500 mg/ml), $75 \%(750 \mathrm{mg} / \mathrm{ml})$ y $100 \%$ $(1000 \mathrm{mg} / \mathrm{ml})$. Después, con una aguja estéril, fueron colocados los discos sobre los cultivos del hongo en las placas Petri preparadas previamente. Se colocaron cuatro discos por cada placa de agar. Hubo dos grupos control para el microorganismo: uno con fluconazol y otro con solución salina; posteriormente, las placas se incubaron a $37^{\circ} \mathrm{C}$ durante 24 horas.

\section{Determinación de la Concentración Mínima Inhibitoria (CMI)}

Para la determinación de la CMI se utilizó el método de dilución en tubos abreviado. Se prepararon seis tubos de ensayo para el microorganismo, cuatro con las concentraciones de $25 \%$, 50 \%, $75 \%$ y $100 \%$. Se añadieron $0.8 \mathrm{ml}$ de cada concentración y luego se realizó la inoculación de $0.2 \mathrm{ml}$ del hongo (en concentraciones semejantes al tubo 0.5 de la escala de Mac Farland) en cada uno de los tubos correspondientes. El quinto tubo correspondió al control con fluconazol $(0.8 \mathrm{ml})$ y se añadió $0.2 \mathrm{ml}$ del hongo. En el sexto tubo se realizó el control sin ningún tratamiento, ańadiendo 1 $\mathrm{ml}$ de cultivo de Candida albicans. Luego, los tubos fueron incubados a $37^{\circ} \mathrm{C}$ por 24 horas, para posteriormente sembrar 0.1 $\mathrm{ml}$ de cada uno de los tubos en 10 placas con Agar Mueller-Hinton, por cada concentración y grupo control. Las placas se colocaron en estufa por 24 horas para observar el crecimiento del hongo mediante el conteo de unidades formadoras de colonias (UFC), considerándose como CMI a la menor concentración en la que no se observaron UFC.

\section{RESULTADOS}

El estudio revela que Candida albicans es sensible al carvacrol debido a que los diámetros de los halos de inhibición son mayores a $8 \mathrm{~mm}$ según la escala de Duraffourd, tal como se observa en la Tabla 1 , que muestra diámetros de los halos de inhibición en $\mathrm{ml}$ del extracto de aceite de orégano, carvacrol, sobre Candida albicans. Además, existe diferencia estadísticamente significativa entre los diámetros de los halos de inhibición hallados de acuerdo a la concentración del carvacrol $(\mathrm{p}<0,05)$, es decir, el efecto es dosis dependiente; conforme aumenta la concentración del carvacrol, aumenta el diámetro del halo de inhibición (Tabla 2).

Respecto a la determinación del CMI, se halló que sí hubo efecto inhibitorio por 
haberse formado un número mínimo de carvacrol sobre Candida albicans fue del UFC en las diferentes concentraciones $100 \%(1000 \mathrm{mg} / \mathrm{ml})$; es la concentración (Tabla 3). La concentración inhibitoria del en la que no se observa UFC (Tabla 4).

\section{TABLA 1}

Diámetros de los halos de inhibición en mm en función de cuatro concentraciones del extracto de aceite de orégano, carvacrol, y control con fluconazol

\begin{tabular}{|c|c|c|c|c|c|}
\hline \multicolumn{6}{|c|}{ MEDICIÓN DE LOS HALOS DE EXHIBICIÓN (mm) DE CANDIDA ALBICANS } \\
\hline \multirow[t]{2}{*}{$\begin{array}{l}\text { Número de } \\
\text { repeticiones }\end{array}$} & \multicolumn{4}{|c|}{$\begin{array}{c}\text { Concentración de extracto de aceite de } \\
\text { orégano "Carvacrol" }(\%)\end{array}$} & \multirow[t]{2}{*}{$\begin{array}{l}\text { Control } \\
\text { Fluconazol }\end{array}$} \\
\hline & 25 & 50 & 75 & 100 & \\
\hline 1 & 7.09 & 12.68 & 13.60 & 21.84 & 6.00 \\
\hline 2 & 8.85 & 11.50 & 13.80 & 23.17 & 6.00 \\
\hline 3 & 8.70 & 10.82 & 13.34 & 20.10 & 6.00 \\
\hline 4 & 9.69 & 11.93 & 14.13 & 21.19 & 6.00 \\
\hline 5 & 8.86 & 11.73 & 13.96 & 24.38 & 6.00 \\
\hline 6 & 8.40 & 12.46 & 13.21 & 21.61 & 6.00 \\
\hline 7 & 7.84 & 12.02 & 13.49 & 21.68 & 6.00 \\
\hline 8 & 7.54 & 12.48 & 14.21 & 22.09 & 6.00 \\
\hline 9 & 9.21 & 11.19 & 13.92 & 22.10 & 6.00 \\
\hline 10 & 8.21 & 11.54 & 13.02 & 20.90 & 6.00 \\
\hline Promedio & 8.44 & 11.84 & 13.67 & 21.91 & 6.00 \\
\hline
\end{tabular}

Fuente: Datos obtenidos por el investigador en 2012

TABLA 2

Prueba de Duncan de acuerdo al diámetro del halo inhibitorio en función de cuatro concentraciones del extracto de aceite de orégano "Carvacrol" y control con Fluconazol

\begin{tabular}{|c|c|c|c|c|c|c|}
\hline \multirow[t]{2}{*}{ Concentraciones } & \multirow[t]{2}{*}{$\mathbf{n}$} & \multicolumn{5}{|c|}{ Grupos para alfa $=0.05$} \\
\hline & & 1 & 2 & 3 & 4 & 5 \\
\hline Fluconazol & 10 & 6.00 & & & & \\
\hline $25 \%$ & 10 & & 8.43 & & & \\
\hline $\mathbf{5 0} \%$ & 10 & & & 11.8 & & \\
\hline $75 \%$ & 10 & & & & 13.6 & \\
\hline $100 \%$ & 10 & & & & & 21.91 \\
\hline
\end{tabular}

Fuente: Datos obtenidos por el investigador en 2012 
TABLA 3

Número de unidades formadoras de colonia (UFC) de Candida albicans en función de cuatro concentraciones del extracto de aceite de orégano, carvacrol, y control con fluconazol

\begin{tabular}{|c|c|c|c|c|c|c|c|c|c|c|c|}
\hline \multirow{3}{*}{$\begin{array}{c}\text { CONCENTRACIÓ } \\
\text { EXTRACTO DE } \\
\text { ACEITE DE } \\
\text { OREGANO } \\
\text { CARVACROL }\end{array}$} & \multicolumn{11}{|c|}{ UNIDADES FORMADORES DE COLONIAS DE CANDIDA ALBICANS } \\
\hline & \multicolumn{11}{|c|}{ NÚMERO DE REPETICIONES } \\
\hline & 1 & 2 & 3 & 4 & 5 & 6 & 7 & 8 & 9 & 10 & PROMEDIO \\
\hline $25 \%$ & 1 & 0 & 1 & 0 & 0 & 1 & 1 & 2 & 4 & 5 & $1.50 \mathrm{UFC}$ \\
\hline $50 \%$ & 2 & 1 & 0 & 0 & 0 & 2 & 0 & 0 & 0 & 0 & $0.50 \mathrm{UFC}$ \\
\hline $75 \%$ & 0 & 1 & 0 & 0 & 0 & 1 & 0 & 0 & 0 & 0 & 0.20 UFC \\
\hline $100 \%$ & 0 & 0 & 0 & 0 & 0 & 0 & 0 & 0 & $\theta$ & 0 & $0.00 \mathrm{UFC}$ \\
\hline Flucozanol & 4595 & 5561 & 4467 & 5978 & 5966 & 5565 & 6630 & 6090 & 5056 & 5215 & 5512.60 UFC \\
\hline
\end{tabular}

Fuente: Datos obtenidos por el investigador en 2012

TABLA 4

Determinación de la concentración mínima inhibitoria (CMI) del extracto de aceite de orégano, carvacrol, sobre Candida albicans

\begin{tabular}{c|c|c}
\hline $\begin{array}{c}\text { Concentración } \\
\text { dextracto etanólico }\end{array}$ & $\begin{array}{c}\text { Promedio de } \\
\text { UFC }\end{array}$ & Observaciones \\
\hline $25 \%$ & 1.50 & \\
\hline $50 \%$ & 0.50 & \\
\hline $75 \%$ & 0.20 & \\
\hline $100 \%$ & 0.00 & CMI \\
\hline
\end{tabular}

Fuente: Datos obtenidos por el investigador en 2012

\section{DISCUSIÓN}

La presente investigación determinó el efecto antibacteriano del extracto de aceite de orégano, carvacrol, frente a Candida albicans, utilizando el método de KirbyBauer o de difusión en disco. Se determinó que el extracto de aceite de orégano tuvo un efecto inhibitorio in vitro frente a Candida albicans, al comparar los halos de inhibición según la escala de Duraffourd para las cuatro concentraciones utilizadas.

También se demostró la actividad antifúngica frente a Candida albicans; sin embargo, estos mecanismos aún no están definidos y además no se cuenta con estudios previos que investiguen la actividad antifúngica del carvacrol. También en este estudio se observó que, a pesar de que la máxima concentración de fluconazol vía endovenosa usada en la actualidad es de $2 \mathrm{mg} / \mathrm{ml}$, a esta concentración in vitro el antifúngico no logró inhibir el crecimiento de los hongos, lo cual podría explicar el porqué de la resistencia a fluconazol de cepas de Candida albicans en nuestra región, coincidiendo con estudios nacionales e internacionales ${ }^{12,15}$. 
En otros estudios de determinación, la actividad antifúngica contra Candida albicans ATCC 10231 se evaluó mediante los métodos de difusión en agar y dilución en agar para la determinación de la CMI. De diez extractos investigados, seis presentaron actividad antifúngica consistente con un diámetro de halos de inhibición $>18 \mathrm{~mm}$ en la concentración al $100 \%(100 \mathrm{mg} / \mathrm{ml})$. De esto se puede deducir que tanto el promedio de los halos de inhibición como la CMI fueron mucho mayores a los hallados en este estudio ${ }^{1,12,16}$.

\section{CONCLUSIÓN}

Se concluye que el extracto de aceite de orégano, carvacrol, al $100 \%$ tiene un efecto antibacteriano in vitro contra Candida albicans.

\section{REFERENCIAS BIBLIOGRÁFICAS}

1. Ahmad S, Khan Z. Invasive candidiasis: A review of nonculture-based laboratory diagnostic methods. Indian J Med Microbiol. 2012; 30:264-269.

2. Araujo J. Actividad antimicrobiana de plantas. Rev. Perú. 2008; 6(1) 6-7.

3. Duraffourd C. Cuaderno de fitoterapia clínica. Barcelona. Masson; 1987.

4. Ferreira BS, de Almeida CG, Faza LP, de Almeida A, Diniz CG, da Silva VL, Grazul RM, Le Hyaric M. Comparative properties of Amazonian oils obtained by different extraction methods. Molecules. 2011; jul 13; 16(7): 5875-85.

5. Gadea I, Cuenca-Estrella M et al. Recomendaciones para el diagnóstico micológico y estudios de sensibilidad a los anti fúngicos. Enferm Infecc Microbiol Clin. 2004; 22,(1) 32-9.

6. Kauffman CA, Carver PL. Antifungal agents in the 1990s. Current status and future developments. Drugs. 1997: 53:539-549.
7. Knoblock K, Pauli A, Iberl N, Wqeigand N, Weis HM. Antibacterial and antifungal properties of essential oil components. J Essent Oil Res. 1989: 1: 119-128.

8. Lambert RJW. Susceptibility testing: inoculum size dependency of inhibition using the Colworth MIC technique. J Appl Microbiol. 2000: 89: 275-279.

9. Manzano GP, Méndez TL, Hernández HF. Antifungal resistance: an emerging problem in México. Gaceta Med Mex. 144(1): 23-26. 2.

10. Martinez A, Ferrer S, Santos I, Jimenez E, Sparrowe J, Regardera J, et al. Antifungal activities of two new azasordarins, GW471552 and GW471558, in experimental models of oral and vulvovaginal candidiasis in immunosuppressed rats. Antimicrob Agents Chemother 2001: 45: 3304-3330.

11. Martínez A, Regardera J, Jiménez E, Immaculada S, Gargallo-Viola D. Antifungal efficacy of GM237354, a sordarin derivative, in experimental oral Candidiasis in immunosuppressed rats. Antimicrob Agents Chemother. 2001: 45: 1008-1013.

12. Mayer FL. Candida albicans pathogenicity mechanism. 2013; 4(2) 119-128.

13. Moyes DL, Naglik JR. Mucosal immunity and Candida albicans infection. Clin Dev Immunol. 2011:9:1-9.

14. Remmal A, Bouchikhi T, Tantaoui-Elaraki A, Ettayebi M. Inhibition of antibacterial activity of essential oils by Tween 80 and ethanol in liquid medium. J Pharm Belg 1993a: 48: 352-356.

15. Remmal A, Tantaoui-Elaraki A, Bouchikhi T, Rhayour K, Ettayebi M. Improved method for the determination of antimicrobial activity of essential oils in agar medium. J Essent Oil Res 1993b: 5: 1179-1184. 